\title{
Climate consequences of hydrogen leakage
}

\author{
Ilissa B. Ocko ${ }^{1}$, Steven P. Hamburg ${ }^{1}$ \\ ${ }^{1}$ Environmental Defense Fund; New York, NY, USA \\ Correspondence to: Ilissa B. Ocko (iocko@edf.org)
}

5 Abstract. Hydrogen is quickly gaining attention as a "clean" fuel that can support a transition to a decarbonized energy system. Given the urgency to decarbonize global energy systems, governments and industry are moving ahead with efforts to increase hydrogen technologies, infrastructure, and applications at an unprecedented pace, including billions in national incentives and direct investments. While zero- and low-carbon hydrogen hold great promise to help solve some of the world's most pressing energy challenges, hydrogen is also a short-lived indirect greenhouse gas whose warming impact is not well-characterized.

10 There are multiple areas of uncertainty. To date, hydrogen's warming effects have been primarily characterized using the GWP-100 metric — which is misleading for short-lived gases, such as hydrogen, as it obscures impacts on shorter timescales. Furthermore, hydrogen is a small molecule known to easily leak into the atmosphere; however, the total amount of leakage in current hydrogen systems remains unknown, with the analytical capacity to accurately measure leakage in situ largely unavailable. Therefore, the net climate benefit of a future hydrogen economy is unknown over the near to medium term. This

15 paper explores the climate implications of hydrogen leakage over all timescales by assessing the change in cumulative radiative forcing from replacing fossil fuel systems with hydrogen applications and estimating temperature responses to leakage using a plausible range of hydrogen leak rates and the latest estimate of hydrogen's radiative efficiency. We also consider the climate impacts from methane leakage when the hydrogen is produced via natural gas with CCUS ('blue' hydrogen) as opposed to renewables and water ('green' hydrogen); both are considered "clean." We find that the climate consequences of hydrogen applications relative to their fossil fuel counterparts strongly depend on time horizon and leakage rate, with vastly different climate outcomes in the near- vs. long-term and for best- vs. worst-case leak rates. For example, worst-case hydrogen leak rates could yield a near-doubling in radiative forcing relative to fossil fuel counterparts in the first five years following the technology switch, but an $80 \%$ decrease in radiative forcing over the following 100 years after deployment. On the other hand, best-case hydrogen leak rates could yield an $80 \%$ decrease in radiative forcing in the first five years. Simple estimates of temperature responses to a $10 \%$ hydrogen leakage rate (a high but plausible level) suggest a theoretical maximum contribution of around a quarter of a degree (C) in 2050 if hydrogen replaces the entire fossil fuel energy system, and at least a tenth of a degree (C) in 2050 if hydrogen accounts for more than half of final energy demand. Thus, a greater understanding of hydrogen's warming impacts at different possible leakage rates is critical to inform where and how to deploy hydrogen effectively in the emerging decarbonized global economy. 


\section{Introduction}

Hydrogen is now considered an essential component in transitioning to a low-carbon global economy and achieving net zero greenhouse gas emissions targets (International Energy Agency, 2021). However, one potential concern has been largely absent in recent conversations and assessments (Anon, 2019; International Energy Agency, 2021; BloombergNEF, 2020; Bartlett and Krupnick, 2020; van Renssen, 2020; World Energy Council, 2021; Hydrogen Council, 2021c; Ueckerdt et al., 2021): the atmospheric warming effects from hydrogen leakage. Scientists have long-known and cautioned that hydrogen has indirect warming impacts (Ehhalt et al., 2001; Derwent et al., 2001, 2006, 2020; Prather, 2003; Schultz et al., 2003; Colella et al., 2005; Wuebbles et al., 2010; Derwent, 2018; Paulot et al., 2021; Field and Derwent, 2021): when it escapes into the atmosphere, it warms the Earth by affecting chemical reactions that increase the amount of greenhouse gases including methane, tropospheric ozone, and stratospheric water vapor. However, the use of standard greenhouse gas potency reporting conventions (i.e. Global

40 Warming Potential; GWP) in many of these studies has considerably downplayed its radiative potency, leading to a perception that impacts are minor. This is because hydrogen is a short-lived gas with an atmospheric lifetime of a few years (Rahn et al., 2003; Derwent et al., 2020; Paulot et al., 2021), and GWP deemphasizes the climatic importance of short-lived species in the near- to medium-term; this is because the most common time horizon employed considers how a pulse of emissions impacts the climate over the following 100 years-long after the gas has left the atmosphere (Alvarez et al., 2012; Ocko et al., 2017).

45 The overall magnitude and thus importance of the short-term warming effects from hydrogen leakage will largely depend on how much hydrogen is ultimately deployed to replace fossil fuel systems and how much is able to leak from the value chain. Currently, hydrogen accounts for only a small fraction of the global economy (International Energy Agency, 2021), but predictions suggest that supply could increase at least tenfold from today's levels by mid-century and account for approximately 20\% of final energy demand and potentially even more (Hydrogen Council, 2017; BloombergNEF, 2020;

50 International Energy Agency, 2021). Unfortunately, there is a dearth of data quantifying hydrogen leakage (Mejia et al., 2020). Hydrogen is thought to leak across the entire value chain, including electrolysers, compressors, liquefiers, storage tanks, geologic storage, pipelines, trucks, trains, ships, and fuelling stations-with the highest rates likely in midstream and downstream sectors (van Ruijven et al., 2011). Empirical data to date on leakage rates from specific infrastructure (such as pipelines, vehicles, storage) are focused on safety concerns, regulations, and risk assessment, which tend to focus on larger leaks, with no commercially available sensing technologies able to detect smaller leaks that would impact the climate but not safety (Mejia et al., 2020).

Hydrogen leakage across the value chain is a concern regardless of production method, and therefore applies to all hydrogen, including "green" hydrogen (hydrogen produced from water using renewable energy; considered "zero-carbon" or "climate neutral"). "Blue" hydrogen production (hydrogen produced from natural gas using CCS technologies; considered "low-

60 carbon") is subject to additional impacts on the energy balance due to residual emissions of carbon dioxide $\left(\mathrm{CO}_{2}\right)$ as well as emissions of methane from the natural gas supply value chain. Methane leakage suffers the same analytical challenges as 
hydrogen given that it is also a short-lived gas that is typically assessed using a long-term perspective, thus overlooking its strong potency in the short-term (Howarth and Jacobson, 2021). The climate effects of methane leakage are often underestimated in hydrogen assessments given that natural gas leak rates are often under reported in national emission inventories (Alvarez et al., 2018; Shen et al., 2021).

Given hydrogen's known indirect greenhouse gas properties and unknown leak rates, we use a metric for looking at the impacts of energy transitions on net radiative forcing over time called Technology Warming Potential (Alvarez et al., 2012) that considers continuous emissions, providing a more realistic understanding of the climate impacts of fuel switching. Furthermore, we estimate temperature responses to different levels of hydrogen deployment and leakage based on a simple

70 approach as there are currently no formal models we are aware of that can simulate the full climate responses to hydrogen emissions.

\section{Hydrogen's indirect greenhouse gas effects}

Previous waves of hydrogen enthusiasm led researchers to explore the unintended atmospheric consequences of a potential hydrogen economy (Prather, 2003; Schultz et al., 2003; Tromp et al., 2003; Colella et al., 2005) given hydrogen's long-

75 established reactivity in the atmosphere (Levy, 1972; Crutzen, 1974) and potential to leak from infrastructure (Prather, 2003). Two consequences have been considered: stratospheric ozone destruction via the formation of stratospheric water vapor, and indirect climate forcings via perturbations to greenhouse gas concentrations.

When hydrogen escapes into the atmosphere, it has two main fates: around 70 to $80 \%$ is estimated to be removed by soils via diffusion and bacteria and the remaining 20 to $30 \%$ is oxidized by reacting with the naturally-occurring hydroxyl radical $(\mathrm{OH})$,

80 yielding an atmospheric lifetime of around a few years (Rahn et al., 2003; Derwent, 2018; Paulot et al., 2021). The oxidation of hydrogen leads to increasing concentrations of greenhouse gases in both the troposphere and stratosphere, as described in Fig. 1 (Derwent, 2018; Derwent et al., 2020; Paulot et al., 2021; Field and Derwent, 2021). In the troposphere, less OH is available to react with methane, and given that methane's reaction with $\mathrm{OH}$ is methane's primary sink, this leads to a longer atmosphere lifetime for methane. Also in the troposphere, the production of atomic hydrogen from hydrogen oxidation leads

85 to a series of reactions that ultimately form tropospheric ozone, another greenhouse gas (see Fig. 1 for details). In the stratosphere, the oxidation of hydrogen increases the amount of water vapor, which has a positive forcing on the climate due to stratospheric cooling from water vapor's absorption of heat. The stratospheric cooling can also lead to an increase in stratospheric polar clouds that enable more ozone-destroying reactions to occur (Derwent, 2018). 


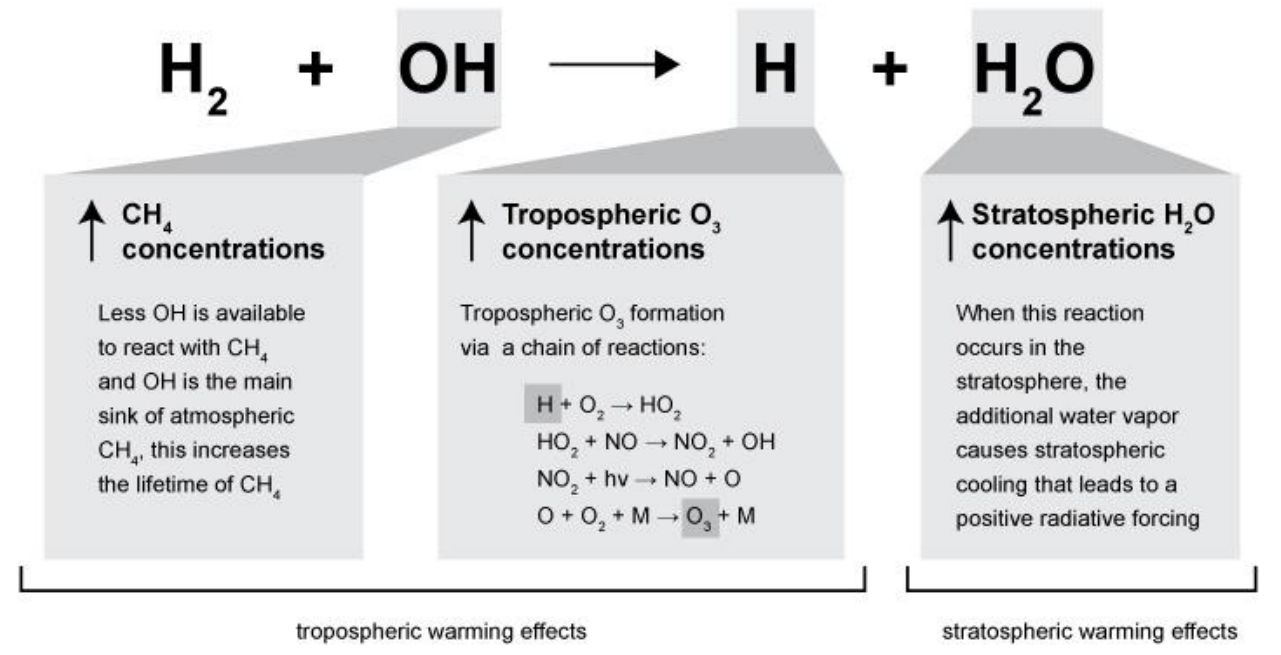

Figure 1: Effects of hydrogen oxidation on atmospheric greenhouse gas concentrations.

The consensus of several studies suggests that risks to stratospheric ozone are minor even with extensive use of hydrogen and high leak rates (Tromp et al., 2003; Warwick et al., 2004; Jacobson, 2008; van Ruijven et al., 2011; Vogel et al., 2011, 2012; Wang et al., 2013; Wuebbles et al., 2010), although Derwent (2018) indicates that more studies are warranted that use a range of state-of-the-science stratospheric ozone models. For studies that investigate climate forcings, only one to date includes both tropospheric and stratospheric effects (Paulot et al., 2021). The others have focused on tropospheric effects, with a few calculating climate forcings for select leakage rates and hydrogen demand scenarios (Prather, 2003; Schultz et al., 2003; Wuebbles et al., 2010), but the majority presenting results in terms of GWP-100 (Derwent et al., 2001, 2006; Derwent, 2018; Derwent et al., 2020; Field and Derwent, 2021). While the consensus among these studies has maintained that the absolute forcing of a hydrogen-intensive economy is relatively minor compared to today's forcings from carbon dioxide and methane emissions, the combination of GWP-100 downplaying hydrogen's true potency and the recent insights into the full atmospheric warming effects of hydrogen emissions warrants a deeper assessment of the climate consequences of hydrogen leakage using more robust metrics and including both tropospheric and stratospheric effects.

In particular, over the past two decades a series of studies used the STOCHEM chemistry transport model to assess and refine estimates of future hydrogen leakage's warming impacts resulting from tropospheric chemistry effects (Derwent et al., 2001, 2006, 2020; Derwent, 2018; Field and Derwent, 2021). The analyses have consistently been carried out as a comparison between a pulse of hydrogen emissions' impact on cumulative radiative forcing over the following 100 years relative to that from a pulse of carbon dioxide emissions-effectively, hydrogen's GWP with a 100-year time horizon (GWP-100). This has led to a general estimate of hydrogen's GWP-100 is $5 \pm 1$, which indicates that a pulse of hydrogen emissions will yield 5 times more warming than an equal (by weight) pulse of carbon dioxide emissions over the following 100 years (Derwent et 
al., 2020). (We note that a recent study arrived at a GWP-100 of 3.3, but it is unclear if this result is due to the specific case study that was investigated in the calculation (Field and Derwent, 2021).) As several previous studies have shown, relying on GWP-100 for understanding the importance of short-lived greenhouse gases relative to carbon dioxide is misleading (Alvarez et al., 2012; Ocko et al., 2017; Ocko and Hamburg, 2019). However, using the data provided by Derwent et al. (2020) for hydrogen's atmospheric lifetime ( 2 years) and its GWP-100 ( $5 \pm 1$ ), we can use the traditional GWP formulas (Forster et al., 2021) to calculate hydrogen's radiative efficiency for tropospheric warming effects: $2.3 \pm 0.5 \mathrm{E}-13 \mathrm{~W} \mathrm{~m}^{-2} \mathrm{~kg}^{-1}$, which is $>100$ times the radiative efficiency of carbon dioxide per unit mass $\left(1.7 \mathrm{E}-15 \mathrm{~W} \mathrm{~m}^{-2} \mathrm{~kg}^{-1}\right.$; (Forster et al., 2021)) and slightly larger than methane's (2.0 E-13 W m-2 $\mathrm{kg}^{-1}$; includes indirect effects but does not include climate-carbon feedbacks; (Forster et al., 2021)).

120 A recent study expanded upon past work by using the GFDL-AM4.1 model (atmospheric component of an earth system model) to estimate hydrogen's influence on Earth's radiative balance considering both tropospheric and stratospheric effects (Paulot et al., 2021). The study estimated hydrogen has a $0.13 \mathrm{~mW} \mathrm{~m}^{-2} \mathrm{ppbv}^{-1}$ radiative efficiency (which converts to $3.64 \mathrm{E}-13 \mathrm{~W} \mathrm{~m}^{-}$ ${ }^{2} \mathrm{~kg}^{-1}$ ) with an atmospheric lifetime of 2.5 years. Two thirds of this warming effect is from tropospheric effects, and the other third is from stratospheric effects. Paulot et al. (2021) found that around half of hydrogen's radiative efficiency is due to 125 lengthening the lifetime of methane in the atmosphere. Comparing the tropospheric portion of hydrogen's radiative efficiency from Paulot et al. (2021) with that from Derwent et al. (2020) shows Paulot's estimate is only 6\% higher, well within the range of Derwent et al. (2020) uncertainty estimates. Based on this latest study, hydrogen's radiative efficiency considering both tropospheric and stratospheric effects is more than 200 times that of carbon dioxide's per unit mass. Using the traditional GWP formulas (Forster et al., 2021), this estimate of hydrogen's radiative efficiency translates to a GWP-100 of around 10 (double

130 that reported by Derwent et al. (2020).

Given hydrogen's short atmospheric lifetime of only a few years, reporting hydrogen's potency in GWP-100 has limited value. One strategy for indicating the potency of short-lived climate pollutants is to report GWPs for two time horizons - one that conveys near-term impacts (most commonly 20-year time horizon) and one that conveys long-term impacts (100 years) (Ocko et al., 2017). Using the GWP formulas, this would translate to a GWP-20/100 of 19/5 for Derwent et al. (2020) (only

135 tropospheric impacts) and 38/10 for Paulot et al. (2021) (both tropospheric and stratospheric effects). However, even a 20-year time horizon is long for a gas that only lasts a few years in the atmosphere. If we instead indicate the GWP over a 10-year time horizon (GWP-10), hydrogen's potency relative to carbon dioxide for a pulse of emissions would increase to 34 and 66 for Derwent et al. (2020) and Paulot et al. (2021), respectively. For even shorter time horizons, hydrogen's GWP can be more than ten times higher than what GWP-100 indicates (Fig. 2). This indicates larger near- and medium-term climate effects that are 140 not conveyed by the traditional GWP-100 approach. This difference is material, given that most policy is currently focused on reaching net zero over these shorter time horizons. 
However, assessing the impact of hydrogen through a pulse of emissions is also problematic. This is because continuous emissions are a better representation of actual hydrogen deployment. To better understand the climate effects of hydrogen over all timescales, one would need to consider the radiative effects of continuous emissions over time (Alvarez et al., 2012). In

145 Fig. 2, we show how the GWPs for hydrogen change over time depending on the time horizon used in the calculation, and compare to an identical approach that uses continuous, rather than pulse, emissions. When continuous emissions are considered as opposed to just one pulse at time $=0$, the potency of hydrogen relative to carbon dioxide is on average double that of the pulse approach (Fig. 2); this is true for long-term effects as well.

Overall, accounting for shorter rather than longer time horizons, continuous rather than pulse emissions, and both stratospheric and tropospheric effects can lead to a radiative potency of hydrogen relative to $\mathrm{CO}_{2}$ that is more than 20 times higher than the most commonly known hydrogen GWP of 5 (which is over 100 years, for pulse emissions, and only considers tropospheric effects). Even for 100-year impacts, accounting for continuous emissions and including stratospheric effects leads to a quadrupling of hydrogen's commonly known GWP, from 5 to 20. Therefore, even the long-term effects of hydrogen leakage are significantly underestimated.

(a)

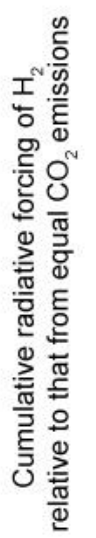

155

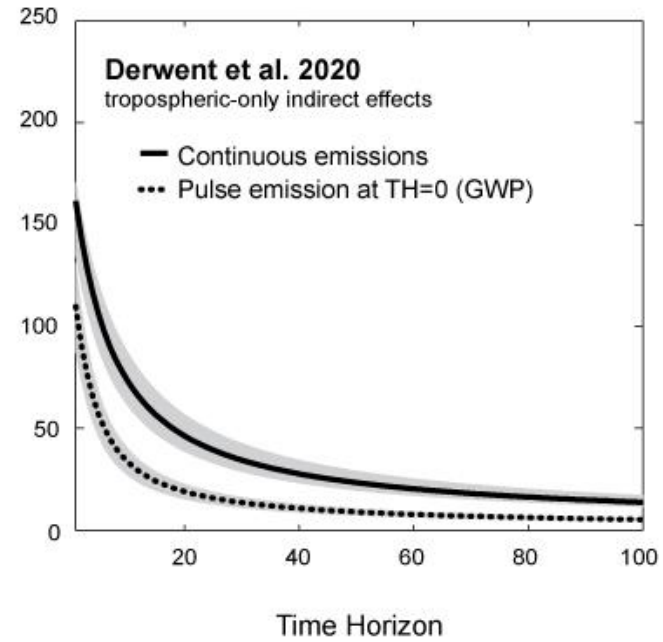

(b)

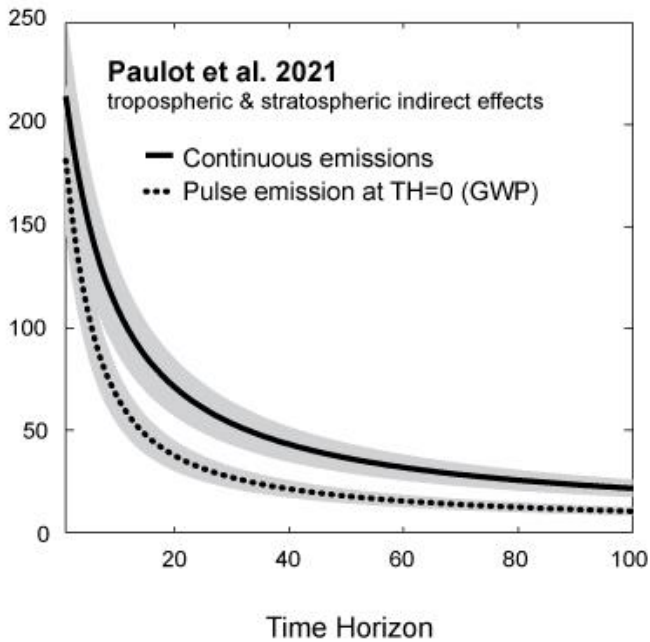

Figure 2: Cumulative radiative forcing of hydrogen relative to carbon dioxide for equal emissions. Solid lines are for continuous emissions of both hydrogen and carbon dioxide, and dotted lines are for a pulse of emissions at time horizon $=0$. Dotted lines correspond to traditional GWP calculations per time horizon. Shaded areas correspond to a $20 \%$ uncertainty in the radiative efficiency of hydrogen. (a) is based on hydrogen's radiative efficiency derived from Derwent et al. (2020), and includes only tropospheric responses to hydrogen oxidation.

160 (a) is based on hydrogen's radiative efficiency derived from Paulot et al. (2021), and includes both tropospheric and stratospheric responses to hydrogen oxidation. 
However, given that hydrogen's radiative effects are entirely indirect, any time horizon shorter than the lifetime of hydrogen (in which the required reactions have not yet taken place) will not provide a meaningful GWP result. Further, while Field and build up. This highlights the need for a more integrated chemistry-climate modelling approach to accurately determine the tropospheric and stratospheric radiative effects of hydrogen leakage in the first several years after emission. The importance of such an approach is enhanced when determining how related factors may change in the future, such as changing concentrations of methane resulting from reduced emissions of methane in response to aggressive policies to address climate goals.

\section{Hydrogen leakage rates}

Given its small molecule size, low molecular weight, high diffusivity, and low viscosity, hydrogen is difficult to contain and can easily leak from infrastructure throughout the value chain (van Ruijven et al., 2011; Bond et al., 2011; Melaina et al., 2013). While fluid dynamics theory suggests that hydrogen can leak 1.3 to 3 times faster than methane (the main component of natural gas) (Swain and Swain, 1992), a recent study focused on low pressure distribution pipes suggests that small leaks in methane and hydrogen may occur at similar rates (Mejia et al., 2020).

There is a paucity of quantitative data addressing in situ hydrogen leakage along the value chain, with empirical measurements to date focused on safety concerns (i.e. large leaks) primarily in confined spaces (Kobayashi et al., 2018). While there are many methods of hydrogen gas sensing (e.g. optical, acoustic, thermal, electrochemical) and several types of sensors exist (Najjar, 2019), there are currently no commercially available sensors that can detect hydrogen leakage at levels well below the threshold for hydrogen gas flammability which is required to characterize leakage in the open. Numerical studies also analyse hydrogen leakage through a safety perspective (Hajji et al., 2015; Parvini and Gharagouzlou, 2015; Chang et al., 2019; Qian et al., 2020) and small leaks of a buoyant gas will likely require new methods to accurately characterize actual leak rates (ppb level as opposed to ppm level).

185 It is very likely that hydrogen leaks throughout the value chain, and unclear—given lack of data — which components contribute most and least to leakage. However, based on first principles of moving a small gas molecule, it is likely that transport of hydrogen is a major source, and previous work suggests that liquified hydrogen could have high leak rates from boil off (Sherif et al., 1997). The DOE Hydrogen delivery scenario analysis model (HDSAM 3.0) assumes several loss rates in their model for different hydrogen components, but it is unclear if it is all lost as hydrogen to the atmosphere (i.e. leakage) or converted into other compounds (Department of Energy, n.d.). Components and loss rates assumed in their model include compressor $(0.5 \%)$, liquefier $(0.5 \%)$, compressed gas terminal $(0.5 \%)$, liquid terminal $(0.25-0.5 \%)$, geologic storage $(0.5 \%)$, refuelling station gas $(0.5 \%)$, refuelling station - liquid (0.3\%/day). For pipelines (transmission and distribution), assumptions are made of loss in mass per mile per year (778 and $156 \mathrm{~kg} \mathrm{H}_{2} \mathrm{mi}^{-1} \mathrm{yr}^{-1}$, respectively). In addition, van Ruijven et al. (2011) synthesize estimates 
of leakage for different delivery methods and a few end uses based on previous studies, for both low leakage and high leakage cases. Estimates include long-distance ship (0-2\%), long-distance pipeline (0.1-5\%), short-distance truck (2-5.5\%), shortdistance pipeline (0.1-5\%), on-board storage (0.3-1\%), and fuel cell and on-board system (0.1-1\%). However, a survey of empirical measurements available makes it clear that we require significantly more robust data to have confidence in these estimates for each component of the value chain.

As such, we have even less confidence on total value chain leakage, which will depend on the configuration of the pathway from production to end use. Of the previous studies that have made assumptions of total hydrogen leakage for the purpose of assessing environmental impacts from a potential hydrogen economy, estimates range from $0.3 \%$ to $20 \%$ for minimum to maximum leakage (Schultz et al., 2003; Tromp et al., 2003; Colella et al., 2005; Wuebbles et al., 2010; van Ruijven et al., 2011; Bond et al., 2011). All studies acknowledge major uncertainty in the estimates due to a lack of data. Further studies have also made assumptions on total value chain leakage citing these previous studies, typically using an upper end of 10\% (Prather, 2003; Derwent et al., 2001, 2020; Paulot et al., 2021). The 20\% total leakage appears to be an outlier suggested by one study (Tromp et al., 2003); Schultz et al. (2003) suggest that only for extreme individual cases like uncontrolled evaporation from liquid hydrogen storage tanks would 10 to $20 \%$ leakage rates be possible. However, the total value chain hydrogen leakage estimated by van Ruijven et al. (2011) based on a per-component configuration (more nuanced than previous estimates) has a maximum of $10 \%$ but does not include leakage from production and compression, as well as elements of storage and end use applications, and therefore this estimate may be too low.

There is also strong reason to believe that hydrogen leaks could be even higher. Extensive measurements of natural gas value chain leaks over the last decade (similar infrastructure, larger molecule) have shown that leakage rates were far higher than recognized by industry (Alvarez et al., 2018). This underestimate is the product of missing both ends of the distribution of leaks: not detecting the many smaller leaks as well as missing fat-tailed emissions resulting from rarer large emission events when the infrastructure does not function as intended, such as pipeline cracks and ruptures. If the hydrogen value chain develops as a replacement for natural gas it is reasonable to expect a similar set of challenges. While hydrogen is an arguably more valuable product given the current cost of producing it, the lack of empirical measurements cannot confirm any assumptions regarding the influence of the cost of lost product on leakage rates, especially if there is no regulatory enforcement.

Further, most of the hydrogen infrastructure needed to achieve decarbonization goals has yet to be built, with plans underway to develop more pipelines and even pump hydrogen into individual homes (United Kingdom. Secretary of State for Business, 2021). Without measurements of hydrogen leakage and in turn knowledge of strategies to mitigate leakage and deploy best practices, we risk developing leaky systems that could significantly contribute to climate change in the near to medium-term. Fortunately, we have an opportunity to get ahead of this issue before the infrastructure and systems are widely deployed. 


\section{Climate implications of hydrogen leakage}

225 To evaluate the importance of the warming effects from hydrogen leakage, it is useful to compare the relative climate impacts from hydrogen applications for a range of potential leak rates to the fossil fuel applications they would be replacing. While the overall magnitude of impact on the climate will depend on how much hydrogen is deployed (amongst other factors such as specific technology, value chain path, leak rate, etc.) the comparison approach is similar to that of a life cycle assessment in that it compares climate impacts from two alternative technologies to help inform decision makers. These types of assessments are often conducted using the traditional GWP-100 approach (e.g. Hydrogen Council, 2021a), but as discussed earlier, a 100year timeframe hides what occurs over shorter time periods and continuous emissions are a better representation of technological deployment. For example, Alvarez et al. (2012) showed that while a natural gas powered light-duty vehicle may be better for the climate over a 100-year period than a gasoline vehicle, if natural gas leakage along the supply chain was as the U.S. Environmental Protection Agency estimated it to be-now shown to be a significant underestimate (Alvarez et al., 2018) - then it would take 80 years before one would see climate benefits from its continuous use relative to the use of a gasoline car.

We use the approach of Alvarez et al. (2012) which considers climate impacts over all timescales of continuous emissions to consider temporal tradeoffs in climate benefits: the Technology Warming Potential. This metric builds on the Global Warming Potential metric and is described in detail in Sect. 4.1.2. We apply this metric to a simple case study to provide a first order analysis of the climate implications over all timescales (from the first few years to a hundred years after) as a result of replacing fossil fuel systems with hydrogen applications assuming a range of leak rates. Given that the absolute warming impact from hydrogen applications will depend on the extent of hydrogen deployment, we also approximate temperature responses to hydrogen emissions through 2050 for several deployment scenarios using the approach used in Paulot et al. (2021) and described in Sect 4.1.3.

\section{4.1 Methodology}

\subsubsection{Emissions assumptions}

To arrive at a first order estimate of the potential climate concern of hydrogen leakage per unit deployed, we explore the impact of consuming $1 \mathrm{~kg}$ of hydrogen continuously every year. We follow related studies that, based on the best available literature, assume leak rates ranging from 1 to 10\% (Derwent et al., 2020; Paulot et al., 2021). However, we note that there is a serious

250 lack of empirical data and the ultimate leakage for each hydrogen application will depend on the specific pathway from hydrogen production to consumption. These levels of leakage correspond to hydrogen emissions of 0.01 and $0.11 \mathrm{~kg}$, respectively, given that $1.01 \mathrm{~kg}$ or $1.1 \mathrm{~kg}$ of hydrogen must be produced for $1 \mathrm{~kg}$ of hydrogen to be consumed in either case. Emissions used in our study can be found in Table 1. For green hydrogen, the only climate pollutant emissions in our analysis are that from hydrogen leakage, but we note that infrastructure build out will contribute to emissions as well. 
255 To determine emissions of methane when considering blue hydrogen production, we assume 3 times the mass of hydrogen is needed in the form of methane for using methane as a feedstock for hydrogen production (Budsberg et al., 2015). This would mean 3 times $1.01 \mathrm{~kg}$ or $1.1 \mathrm{~kg}$ depending on the hydrogen leakage which will determine how much hydrogen needs to be produced to have $1 \mathrm{~kg}$ consumed (see Table 1). We then use a range of 1 to $3 \%$ for methane leakage per unit methane used to produce hydrogen, based on the latest understanding of upstream natural gas leakage from oil and gas production as well as distribution of natural gas (Alvarez et al., 2018), which would result in $0.031 \mathrm{~kg}$ methane emissions per $1 \mathrm{~kg}$ hydrogen deployed for best-case leaks for both, and $0.111 \mathrm{~kg}$ for worst-case for both. However, we conservatively assume that half of the replaced fossil fuel applications are natural gas-based, and therefore the net difference in methane leakage from blue hydrogen production is $50 \%$, accounting for 0.016 and $0.056 \mathrm{~kg}$ increase in methane emissions, respectively. Further, we omit residual carbon dioxide emissions from imperfect CCUS technologies to retain simplicity and be conservative, but this would increase the climate impacts of blue hydrogen consumption depending on the efficiency and the permanence of storage.

\begin{tabular}{|c|c|c|c|c|c|}
\hline \multirow[t]{2}{*}{ Unit: $\mathrm{kg} \mathrm{yr}^{-1}$} & & \multicolumn{2}{|c|}{ GREEN HYDROGEN } & \multicolumn{2}{|c|}{ BLUE HYDROGEN } \\
\hline & & Best-case leaks & Worst-case leaks & Best-case leaks & Worst-case leaks \\
\hline \multirow{3}{*}{ Hydrogen } & Produced & 1.01 & 1.1 & 1.01 & 1.1 \\
\hline & Consumed & 1 & 1 & 1 & 1 \\
\hline & Emitted & 0.01 & 0.11 & 0.01 & 0.11 \\
\hline \multirow{3}{*}{ Methane $^{\mathrm{a}}$} & Produced & 0 & 0 & 3.06 & 3.7 \\
\hline & Consumed & 0 & 0 & 3.03 & 3.3 \\
\hline & Emitted & 0 & 0 & 0.016 & 0.056 \\
\hline $\begin{array}{l}\text { Carbon } \\
\text { Dioxide }^{b}\end{array}$ & $\begin{array}{l}\text { Avoided } \\
\text { from } \mathrm{H}_{2} \\
\text { consumed }\end{array}$ & 11 & 1 & 11 & 11 \\
\hline
\end{tabular}

Table 1: Continuous emissions used in analysis for replacing fossil fuel systems with a unit of hydrogen. Green hydrogen includes only hydrogen leakage with a best-case leak rate of $1 \%$ and a worst-case leak rate of $10 \%$, and blue hydrogen includes both hydrogen and methane leakage with a best-case of $1 \%$ for both and a worst-case of $10 \%$ and $3 \%$, respectively. Given that there will be some upstream natural gas leakage associated with the fossil fuel technologies, we conservatively assume that $50 \%$ of methane leakage from blue hydrogen production would have occurred in the fossil fuel case as well, therefore with a net increase of only $50 \%$ of the methane leaks.

${ }^{\text {a }}$ We assume 3 times the mass of hydrogen is needed in the form of methane for using methane as a feedstock for hydrogen production (Budsberg et al., 2015).

${ }^{\mathrm{b}}$ We use estimates from the Hydrogen Council (2017) that quantify avoided carbon dioxide emissions from a scenario of replacing $18 \%$ of final fossil fuel-derived energy demand in 2050 with hydrogen applications to calculate avoided $\mathrm{CO}_{2}$ emissions from a unit of hydrogen deployment. They estimate that a consumption of 550 million metric tonnes of hydrogen can avoid 6 gigatonnes of carbon dioxide emissions 
annually. Replaced fossil fuel systems in their analysis include segments of transport, industry, power, and building energy systems; half of avoided carbon dioxide emissions come from hydrogen applications in the transport sector and a third is from industry.

To estimate how much carbon dioxide emissions are avoided from deployment of one unit of hydrogen (which will ultimately depend on the specific technology), we use estimates from the Hydrogen Council (2017) that quantify avoided carbon dioxide emissions from a scenario of replacing $18 \%$ of final fossil fuel-derived energy demand in 2050 with hydrogen applications. They estimate that a consumption of 550 million metric tonnes of hydrogen can avoid 6 gigatonnes of carbon dioxide emissions annually. Replaced fossil fuel systems in their analysis include segments of transport, industry, power, and building energy systems; half of avoided carbon dioxide emissions come from hydrogen applications in the transport sector and one third is from industry. Using their data provides an estimate of $11 \mathrm{~kg} \mathrm{CO}_{2}$ avoided per $1 \mathrm{~kg} \mathrm{\textrm {H } _ { 2 }}$ consumed, which we use in our analysis (see Table 1). We note that we do not include avoided hydrogen emissions from displaced fossil fuel combustion, and more research is required to determine the net increase in hydrogen emissions.

\begin{tabular}{|c|c|c|c|c|c|c|c|c|c|}
\hline Unit: $\mathrm{Mt} \mathrm{yr}^{-1}$ & & & 2020 & 2025 & 2030 & 2035 & 2040 & 2045 & 2050 \\
\hline \multirow{4}{*}{ Scenario $1^{\mathrm{a}}$} & \multicolumn{2}{|l|}{ Consumed } & 0 & 40 & 80 & 120 & 190 & 330 & 550 \\
\hline & \multirow{3}{*}{ Emitted } & $1 \%$ leak rate & 0 & 0 & 1 & 1 & 2 & 3 & 6 \\
\hline & & $5 \%$ leak rate & 0 & 2 & 4 & 6 & 10 & 17 & 29 \\
\hline & & $10 \%$ leak rate & 0 & 4 & 9 & 13 & 21 & 37 & 61 \\
\hline \multirow{3}{*}{ Scenario $2^{\mathrm{b}}$} & \multirow{3}{*}{ Emitted } & $1 \%$ leak rate & 0 & 1 & 2 & 3 & 5 & 8 & 14 \\
\hline & & $5 \%$ leak rate & 0 & 5 & 10 & 16 & 25 & 43 & 72 \\
\hline & & $10 \%$ leak rate & 0 & 11 & 22 & 33 & 53 & 91 & 152 \\
\hline Scenario $3^{c}$ & \multicolumn{2}{|l|}{ Consumed } & 0 & 218 & 436 & 655 & 1036 & 1800 & 3000 \\
\hline
\end{tabular}

Table 2: Hydrogen consumption scenarios (green and blue combined) and hydrogen emissions for different leak rates.

a Scenario 1 is the hydrogen "vision" outlined by Hydrogen Council $(2017,2021)$, which is a demand of 550 Mt in 2050 to replace segments of fossil-fuel powered transportation, industry, and the power sector and supply $18 \%$ of final energy demand globally.

${ }^{\mathrm{b}}$ Scenario 2 is an upper-end projection by BloombergNEF (2020) for hydrogen supplying all the unlikely-to-electrify sectors in the economy, which is a demand of $1370 \mathrm{Mt}$ in 2050 and would supply around $45 \%$ of final energy demand globally. For the growth between 2020 and 2050, we apply the overall trend projected by Hydrogen Council (2021) for Scenario 1.

${ }^{c}$ Scenario 3 is the theoretical maximum of using hydrogen to supply the entire final energy demand in 2050 , which we estimate to be 3000

295 Mt based on the estimates of hydrogen demand as a percent of final energy demand provided by Hydrogen Council (2017, 2021) and BloombergNEF (2020), which are 3055 Mt and 2900 Mt, respectively. For the growth between 2020 and 2050 , we apply the overall trend projected by Hydrogen Council (2021) for Scenario 1. 
To estimate the absolute warming impacts for different levels of hydrogen consumption through 2050, we consider three scenarios (Table 2). The first scenario is the hydrogen "vision" outlined by Hydrogen Council (Hydrogen Council, 2017, 2021b), which is a demand of $550 \mathrm{Mt}$ in 2050 to replace segments of fossil-fuel powered transportation, industry, and the power sector and supply $18 \%$ of final energy demand globally (640 EJ final energy demand estimated in 2050 for $2{ }^{\circ} \mathrm{C}$ pathway). This is a similar projection to the $>500 \mathrm{Mt}$ demand projected by International Energy Agency (2021) as a means to decarbonize the global economy and achieve net zero by mid-century goals. The second scenario is an upper-end projection by BloombergNEF (2020) for hydrogen supplying all the unlikely-to-electrify sectors in the economy, which is a demand of $1370 \mathrm{Mt}$ in 2050 and would supply around $45 \%$ of final energy demand globally. The third scenario is the theoretical maximum of using hydrogen to supply the entire final energy demand in 2050, which we estimate to be $3000 \mathrm{Mt}$ based on the estimates of hydrogen demand as a percent of final energy demand provided by Hydrogen Council (2017) and BloombergNEF (2020), $3055 \mathrm{Mt}$ and $2900 \mathrm{Mt}$, respectively. For these scenarios, we combine green and blue hydrogen demand and ignore grey hydrogen that should be phased out. We therefore assume near-zero green and blue hydrogen in 2020, and for the growth between 2020 and 2050, we apply the overall trend projected by Hydrogen Council (2021b) for the 550 Mt demand in 2050 scenario to the other two scenarios. When considering climate impacts, we only account for emissions from hydrogen leakage for total hydrogen demand, and we consider three leak rate levels: $1 \%, 5 \%$, and $10 \%$.

\subsubsection{Radiative forcing comparisons}

315 We use the Technology Warming Potential (TWP) to calculate the relative climate impacts from hydrogen applications to that from the fossil fuel applications that they would be replacing for the case study described in Sect. 4.1.1 (continuous deployment of a unit of hydrogen relative to the $\mathrm{CO}_{2}$ emissions avoided). This metric calculates the cumulative radiative forcing of continuous emissions of greenhouse gases over time based on their decay functions and radiative efficiencies, and is described in detail in Alvarez et al. (2012). TWP uses the same fundamental physics as GWP but conveys impacts over time rather than for one select time horizon, and for continuous emissions rather than a pulse of emissions. Several studies have used this metric to assess the climate impacts of different technologies that emit multiple greenhouse gases with varying atmospheric lifetimes, to show how the climate impacts of specific technologies change over time relative to one another (Alvarez et al., 2012; Camuzeaux et al., 2015; Ocko and Hamburg, 2019).

The results are presented as a ratio of climate impacts (using cumulative radiative forcing as a proxy) over time between two different technologies (in our case, this would be hydrogen applications vs. fossil fuel applications). A TWP of greater than 1 indicates that the alternative technology (in this case hydrogen) has larger climate warming impacts at time $t$ than the original technology, and vice versa for less than 1 . In our analysis, we present the results as a percent change in climate impacts (cumulative radiative forcing) from the original technology, such that $1=0 \%$ change (or equal), $2=100 \%$ increase, etc. 
Radiative properties and atmospheric lifetimes used in the analysis can be found in Table 3. We use the radiative efficiency

and atmospheric lifetime for hydrogen that are estimated in Paulot et al. (2021), given that the tropospheric effects are consistent with Derwent et al. (2020), and Paulot et al. (2021) include stratospheric effects as well. While Paulot et al. (2021) does not indicate an uncertainty range for their estimated radiative efficiency of hydrogen, we apply a $20 \%$ uncertainty for two reasons: (1) this is the uncertainty that Derwent et al. (2020) applied to tropospheric warming effects from hydrogen, and (2) the stratospheric effects from hydrogen oxidation are similar to methane oxidation, and the latest science suggests a $14 \%$ uncertainty in chemical responses contributing to methane's radiative efficiency (Forster et al., 2021).

Further, given that the effects of hydrogen emissions are entirely indirect, we average the climate impacts over the first five years after initial emission to account for the individual timelines in chemical responses and to remain conservative during the first few years where hydrogen potency would strongly outweigh that of carbon dioxide if considered an instantaneous effect (recall that the radiative efficiency of hydrogen is around 200 times that of carbon dioxide for equal mass). For example, Field and Derwent (2021) suggest that the tropospheric ozone response is immediate, but that the methane response takes a few years to reach its full potential.

Methane and carbon dioxide radiative properties and atmospheric lifetimes are taken from Forster et al. (2021), but we do not include climate-carbon feedbacks associated with methane to be consistent with what is included with hydrogen. We note that far less work has gone into refining hydrogen's radiative impacts compared to methane and carbon dioxide, and we hope that this paper inspires more research into hydrogen's impacts on Earth's energy balance to provide more confidence in estimates.

\subsubsection{Temperature response estimates}

In the absence of models capable of interactively simulating the chemistry, radiation, and temperature responses in the full atmosphere to hydrogen emissions, we apply the simple approach used by Paulot et al. (2021) to approximate temperature responses to the three hydrogen demand scenarios discussed in Sect. 4.1.1. This method uses the best estimates of the longterm increase in global surface temperature (equilibrium climate sensitivity; ECS) and radiative forcing from a doubling of $\mathrm{CO}_{2}$ concentrations and assumes that hydrogen would have a similar efficacy. The CMIP6 models suggest a best estimate of $3.78 \pm 1.08{ }^{\circ} \mathrm{C}$ for the ECS and a $3.93 \mathrm{~W} \mathrm{~m}^{-2}$ effective radiative forcing for a doubling of $\mathrm{CO}_{2}$ (Forster et al., 2021). This suggests a climate efficacy of $0.96{ }^{\circ} \mathrm{C}\left(\mathrm{W} \mathrm{m}^{2}\right)^{-1}$. To estimate temperature responses to hydrogen emissions, we multiply this efficacy with the hydrogen effective radiative efficiency estimated in Paulot et al. (2021) per unit of emission per year (0.84 $\left.\mathrm{mW} \mathrm{m}{ }^{-2}\left(\mathrm{Tg} \mathrm{yr}^{-1}\right)^{-1}\right)$ and the hydrogen emissions per year based on the leak rate for each hydrogen demand scenario (Table 2). For uncertainty estimates, we use a $20 \%$ uncertainty in the hydrogen effective radiative efficiency as discussed in Sect. 4.1.2. 


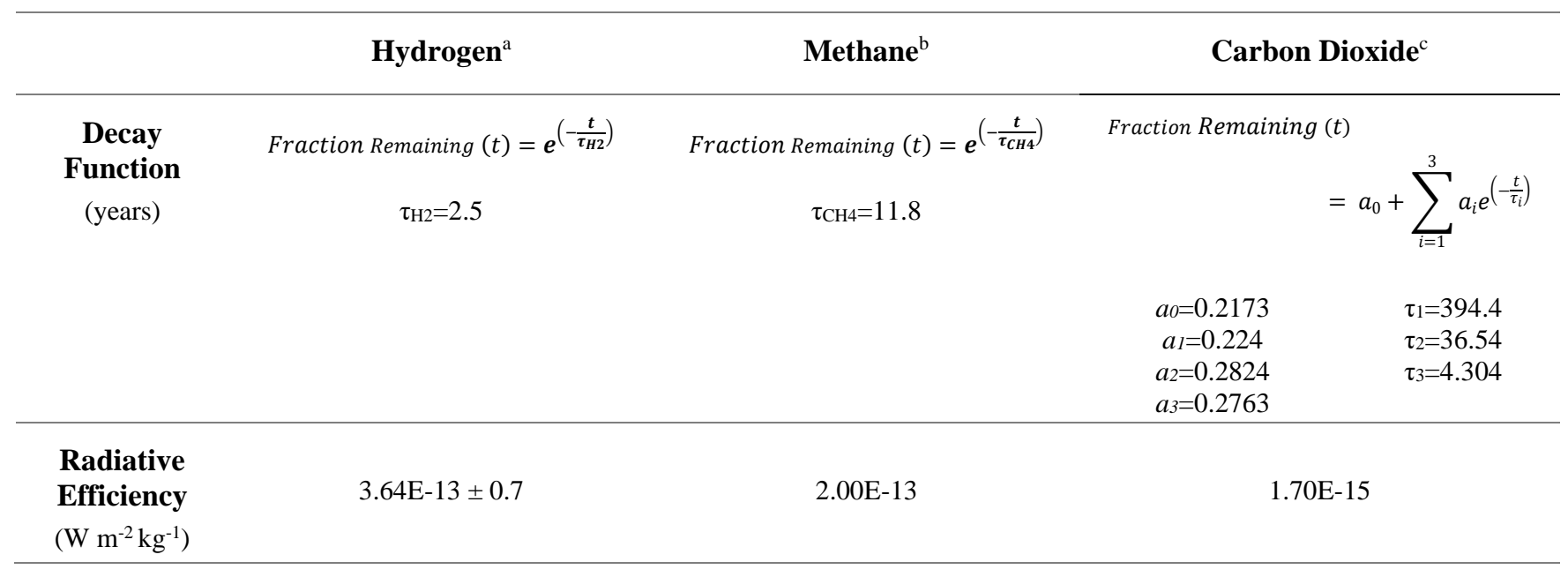

Table 3: Decay functions and radiative efficiencies used in analysis.

${ }^{a}$ Hydrogen decay function from (Shindell et al., 2013). Hydrogen atmospheric lifetime and radiative efficiency are from (Paulot et al., 2021)

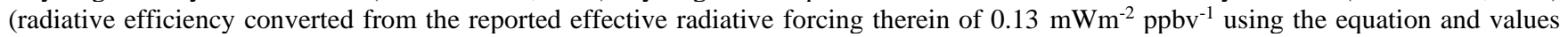
provided in the IPCC AR5 WGI Chapter 8 Supplemental Material; page 8SM-15 (Shindell et al., 2013). A 20\% uncertainty is applied to hydrogen's radiative efficiency following Derwent et al. (2020).

${ }^{\mathrm{b}}$ Methane decay function, atmospheric lifetime, and radiative efficiency (including direct and indirect) from (Forster et al., 2021). Note that carbon cycle adjustment, which would increase the warming potential of methane slightly, is not included in our calculations, because it is not included in the hydrogen's radiative efficiency.

${ }^{\mathrm{c}}$ Carbon dioxide decay function from (Shindell et al., 2013). Carbon dioxide radiative efficiency from (Forster et al., 2021).

\subsection{Results}

\subsubsection{Replacing fossil fuel systems with hydrogen applications}

370 The results of our analysis of the relative climate impacts (using cumulative radiative forcing as a proxy) over time from continuous emissions from replacing fossil fuel applications with their hydrogen counterparts are shown in Fig. 3. If there were zero climate pollutant emissions from the hydrogen applications, the result would be a $-100 \%$ change in cumulative radiative forcing, and if there was no replacement the result would be $0 \%$. If the climate pollutant emissions from hydrogen yield more (less) warming than the fossil fuels over a particular time period, it would amount to a positive (negative) percent change in cumulative radiative forcing.

The benefit of the Technology Warming Potential method is that we can analyse climate impacts over multiple time periods of interest - in the near-, medium-, and long-term—insights that are not available with the use of the GWP-100 metric. This is important when short-lived climate pollutants are emitted as they are often reported and assessed based on the long-term impact of a pulse emission, which overlooks their true impacts during the time they are active in the atmosphere. 
Overall, any amount of hydrogen leakage will detract from the climate benefits from avoided carbon dioxide emissions to some degree, but there are vastly different outcomes in the years following the technology switch-favourable and unfavourable - depending on the total leakage. For example, we find that a best-case scenario for green hydrogen (produced via renewable electricity and water) applications of around $1 \%$ leaked per unit $\mathrm{H}_{2}$ deployed could yield an $84 \pm 3 \%$ decrease in warming in the first five years compared to the warming that would have occurred from the $\mathrm{CO}_{2}$ emissions of the displaced fossil fuel system. By contrast, a worst-case scenario of around $10 \%$ leaked per unit $\mathrm{H}_{2}$ deployed would yield a $74 \pm 35 \%$ increase in warming over the first five years; based on the uncertainty ranges for hydrogen radiative efficiency, this could mean a doubling in radiative forcing at the upper end and still a net increase in warming at the lower end. These are quite different outcomes depending on leakage rate and indicate that green hydrogen is not inherently climate neutral. More attention is needed to measure and minimize hydrogen leakage as hydrogen efforts are ramped up.

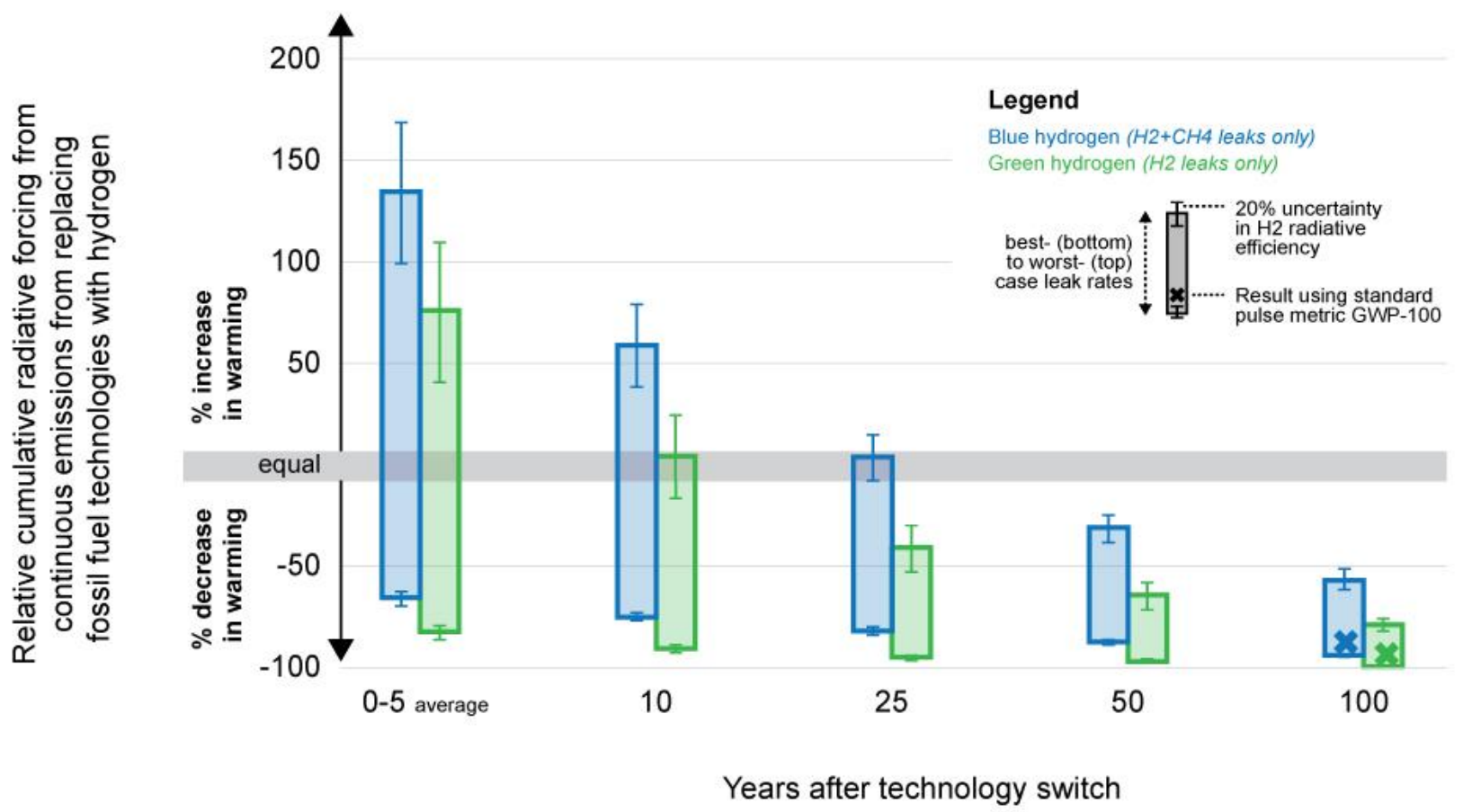

Figure 3: Relative climate impact over time from replacing fossil fuel systems with green or blue hydrogen. Ratio of cumulative radiative forcing of continuous emissions from deploying $1 \mathrm{~kg}$ of $\mathrm{H}_{2}$ continuously replace fossil fuel systems and thereby avoid 11 $\mathrm{kgCO}_{2} / \mathrm{kgH}_{2}$ (see Table 1). Climate impacts from green hydrogen encompass a range of plausible leak rates from $1 \%$ to $10 \%$ per unit $\mathrm{H}_{2}$ deployed and for blue hydrogen also include methane leak rates from $1 \%$ to 3\% per unit methane consumed. See Table 1 for more details on emissions assumptions and Table 3 for radiative properties and decay functions used. Error bars represent a 20\% uncertainty in hydrogen's radiative efficiency. Corresponding GWP-100-derived climate impacts are shown using the " $\mathrm{x}$ " marker. 
Alternatively, if hydrogen is produced using natural gas as a feedstock with CCUS ('blue' hydrogen), residual emissions of $\mathrm{CO}_{2}$ as well as emissions of methane from upstream and midstream natural gas leakage would add to the climate impact of hydrogen leakage (Fig. 3). If we include best- and worst-case methane leakage rates (1\% and 3\% per unit methane consumed, respectively; we also conservatively assumed that half of the replaced fossil fuel applications are natural gas-based and therefore the net difference in methane leakage is 50\%) in the analysis of climate impacts over time from hydrogen deployment, we find that during the first five years, the best-case scenario suggests a $67 \pm 3 \%$ decrease in warming effects relative to that from the fossil fuel counterparts, and a $133 \pm 35 \%$ increase in warming for the worst-case scenario; this could mean a doubling of radiative effects during this time period even if the radiative efficiency is $20 \%$ lower than what is currently estimated by Paulot et al. (2021) (Fig. 3).

In addition to the strong dependency of the climate outcome on leakage rates, the time horizon of interest also matters greatly, because over time the benefits of hydrogen applications are larger due to the prevention of the build-up of carbon dioxide in the atmosphere in favour of a short-lived gas that doesn't accumulate over time. For example, worst-case green (blue) hydrogen may increase cumulative radiative forcing by $74 \pm 35 \%(133 \pm 35 \%)$ in the first five years relative to the fossil fuel applications

410 it is replacing, but over the following 100 years it decreases cumulative radiative forcing by $79 \pm 4 \%$ ( $57 \pm 4 \%)$. However, with worst-case leak rates, it still takes more than a decade to see climate benefits of green hydrogen applications and more than 25 years to see climate benefits of blue hydrogen applications (partly due to the decade-long lifetime of methane) when compared to the climate impacts from the fossil fuel systems that were replaced (Fig. 3). While short-term climate warming impacts - followed by long-term climate change mitigation impacts - may lead to an eventual beneficial outcome, the shortterm warming may lead to climate impacts that cause more socioeconomic and environmental damages in the near-term that are not necessarily reversible (Fischer et al., 2021).

On timescales of several decades after the switched technology, this is when we would likely see climate benefits from both green and blue hydrogen applications regardless of leakage rate. However, even the standard GWP-100 approach undervalues the cumulative radiative forcing over a 100-year time period given its reliance on pulse, instead of continuous, emissions (Fig. 3). For example, a worst-case blue hydrogen case could yield only a decrease in warming of $57 \pm 4 \%$ even after 100 years of replacing fossil fuel technologies, but GWP-100 suggests a decrease in warming of $86 \%$. This could strongly affect the choice of whether or not to deploy hydrogen in applications that have multiple "clean" options. Therefore, even if hydrogen leakage is considered in decarbonization assessments going forward, continuing to use GWP-100 to calculate climate effects will not only overlook near- and mid-term impacts on the climate, but it will underestimate long-term climate impacts of continuous leaks as well. 


\subsubsection{Temperature responses to a future hydrogen economy}

Global-mean surface air temperature responses from 2020 to 2050 to the three hydrogen consumption scenarios using the approach discussed in Sect. 4.1.3 are shown in Fig. 4. For Scenario \#1 (hydrogen supplies $20 \%$ of final energy demand globally in 2050), surface temperature impacts in 2050 from hydrogen leakage alone could range from $0.005 \pm 0.001{ }^{\circ} \mathrm{C}$ for $1 \%$ leakage to $0.05 \pm 0.01{ }^{\circ} \mathrm{C}$ for $10 \%$ leakage. For Scenario \#2 (hydrogen supplies $\sim 50 \%$ of final energy demand globally in 2050), surface temperature impacts in 2050 from hydrogen leakage alone could range from $0.01 \pm 0.02{ }^{\circ} \mathrm{C}$ for $1 \%$ leakage to $0.12 \pm 0.03{ }^{\circ} \mathrm{C}$ for $10 \%$ leakage. And for Scenario \#3 (hydrogen supplies entire final energy demand globally in 2050), surface temperature impacts in 2050 from hydrogen leakage alone could range from $0.02 \pm 0.04{ }^{\circ} \mathrm{C}$ for $1 \%$ leakage to $0.27 \pm 0.05{ }^{\circ} \mathrm{C}$ for $10 \%$ leakage. While Scenario \#3 is a theoretical maximum, it provides insight into how significant a contribution hydrogen leakage could be to increasing Earth's temperature if hydrogen technologies are relied on heavily and we aren't paying attention to leakage.

(a)

(b)
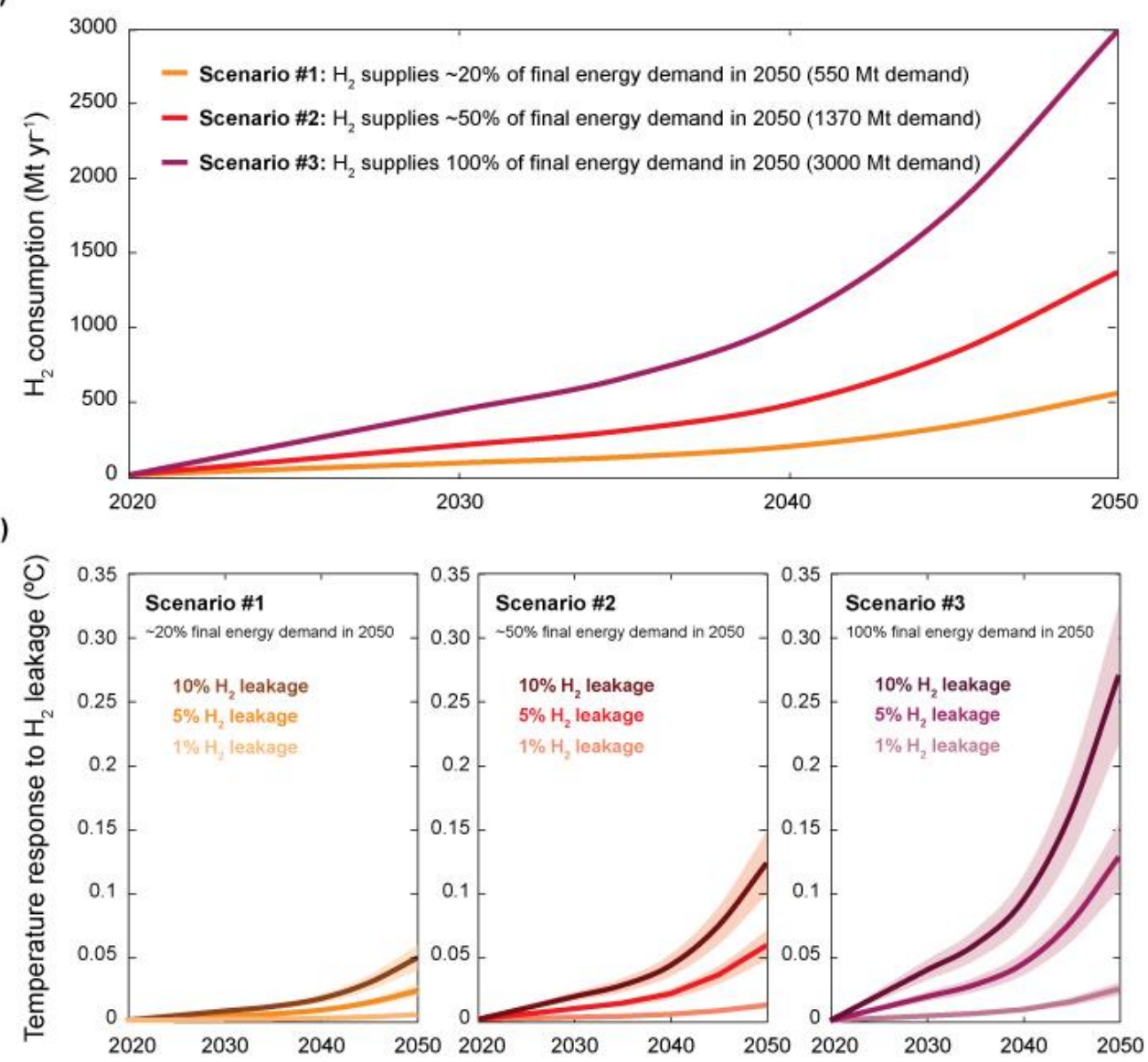

Figure 4: Temperature responses to three hydrogen demand scenarios for various leak rates. Details and sources of scenarios can be found in Table 2 . Shaded region in (b) represents a $20 \%$ uncertainty in hydrogen's radiative efficiency. 
440 Fig. 5 shows the anticipated temperature increase in 2050 based on leakage rate and level of hydrogen demand. For $1 \%$ total leakage, we would expect $0.0024 \pm 0.004{ }^{\circ} \mathrm{C}$ per $10 \%$ final energy demand supplied by hydrogen with a maximum of $0.024 \pm$ $0.004{ }^{\circ} \mathrm{C}$ for a global energy demand that relies exclusively on hydrogen. For $5 \%$ total leakage, we would expect $0.013 \pm 0.003$ ${ }^{\circ} \mathrm{C}$ per $10 \%$ final energy demand supplied by hydrogen with a maximum of $0.13 \pm 0.03{ }^{\circ} \mathrm{C}$. And for $10 \%$ total leakage, we would expect $0.03 \pm 0.005{ }^{\circ} \mathrm{C}$ per $10 \%$ final energy demand supplied by hydrogen with a maximum of $0.27 \pm 0.05{ }^{\circ} \mathrm{C}$. If

445 hydrogen applications supply around half of final energy demand globally in 2050 (an upper estimate by BloombergNEF (2020)), hydrogen applications could cause at least a tenth of a degree (C) of warming for $10 \%$ leakage. For context, this amount of warming could offset the avoided warming in 2050 from deploying all cost-effective options to mitigate methane emissions globally over the next decade - which otherwise could have slowed down global-mean warming rates by up to $15 \%$ (Ocko et al., 2021), or the avoided warming anticipated from the phasing out of hydrofluorocarbons (HFCs) (Xu et al., 2013).

450 This amount of warming $\left(\sim 0.1^{\circ} \mathrm{C}\right)$ is also equal to the amount of warming projected in 2100 from carbon dioxide emissions from international shipping and aviation combined in the absence of climate action (Ivanovich et al., 2019). However, if leakage does not exceed $1 \%$ the temperature response could be an order of magnitude smaller.

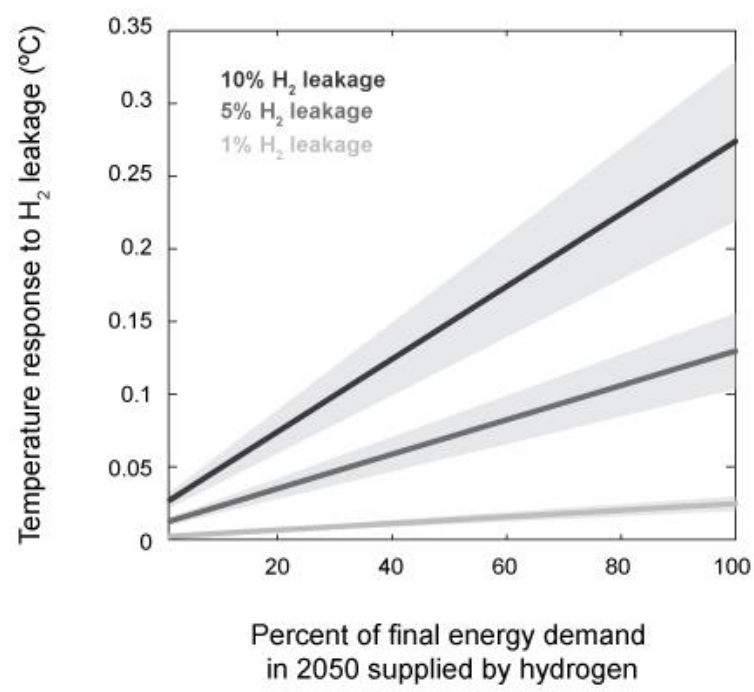

Figure 5: Temperature responses in 2050 depending on hydrogen leak rate and level of hydrogen deployment. Shaded region 455 represents a $20 \%$ uncertainty in hydrogen's radiative efficiency.

\section{Conclusions}

Drawing on recent advances in hydrogen's indirect warming efficiency estimates (Paulot et al., 2021), the only available estimates of plausible total value chain leakage (van Ruijven et al., 2011), and a metric that improves upon GWP by accounting for continuous emissions and climate impacts over time (Alvarez et al., 2012), we analyse the relative climate impacts over all 
timescales from replacing fossil fuel technologies with their hydrogen counterparts based on a unit of $\mathrm{H}_{2}$ deployed relative to the avoided $\mathrm{CO}_{2}$ emissions. To provide a sense of the overall magnitude of impact on global temperatures from future hydrogen leakage, we also estimate the temperature responses based on leak rate and deployment level.

We find that hydrogen leakage may have the potential to considerably undermine any near- and mid-term climate benefits when replacing fossil fuel systems with zero- and low-carbon hydrogen applications. Additionally, the climate benefits from avoided $\mathrm{CO}_{2}$ emissions are far less than what is currently assumed based on GWP-100-derived assessments. In fact, if leaks are moderately high, even green hydrogen may initially yield more warming than would the use of the fossil fuel system it replaces. The impacts are even more pronounced for 'blue' hydrogen, given that methane leakage suffers the same analytical challenges as hydrogen as result of being a short-lived gas (Alvarez et al., 2018).

The extent of the near- and mid-term warming effects from hydrogen leakage - and the extent to which they could limit or offset the anticipated slowdown in the rate of warming from replacing fossil fuel systems with hydrogen depends on how much hydrogen is ultimately deployed to replace fossil fuel systems and the magnitude of leak rates. To our knowledge, no model is currently capable of interactively simulating the chemistry, radiative forcings, and temperature impacts from hydrogen emissions into the full atmosphere. In the absence of such models, we approximate what the temperature responses may be to a future hydrogen economy assuming the efficacy of hydrogen is similar to $\mathrm{CO}_{2}$.

475 For the most likely hydrogen deployment scenario (the "hydrogen vision" by Hydrogen Council (2017) and consistent with International Energy Agency (2021) projections; accounts for 20\% of final energy demand in 2050), 10\% hydrogen leakage could cause $0.06 \pm 0.01{ }^{\circ} \mathrm{C}$ of warming in 2050 . However, if hydrogen is able to replace more than $50 \%$ of fossil fuel systems in 2050 (upper-end estimate from BloombergNEF (2020)) and if hydrogen leakage is high (10\%), hydrogen applications could contribute more than a tenth of a degree (C) to global temperature rise. But this could be halved or an order of magnitude smaller if total leakage is limited to $5 \%$ or $1 \%$, respectively.

Overall, our analysis should be considered a first step towards understanding the importance of hydrogen leakage on the climate system. Our results indicate that the issue of potential climate consequences from hydrogen leakage deserves more attention focused on advancing the science of hydrogen's indirect climate effects and improving estimates of hydrogen leakage throughout the value chain. This is especially true given that it may be possible to prevent leakage in some applications and it is easier to address and minimize hydrogen leakage when designing a system versus retrofitting one.

Our analysis suggests that five key actions can help minimize hydrogen warming effects and therefore maximize climate benefits of a future hydrogen economy:

(1) pursue the research required to reduce the uncertainty in hydrogen's indirect radiative effects and develop the capability to model temperature responses to hydrogen emissions (there has been limited attention to hydrogen's 
warming effects in the atmosphere relative to other greenhouse gases, and given the risk of leakage more attention is warranted);

(2) employ climate metrics that effectively reflect the role that hydrogen could play in meeting net zero goals in the desired time frames - this means not exclusively relying on GWP-100;

(3) improve quantification of hydrogen leakage rates (the lack of accurate data quantifying hydrogen leakage across the value chain remains a serious challenge in understanding the magnitude of the impact; a critical first step is developing technologies that can be taken into the field to accurately measure hydrogen leakage which will require equipment with a low-detection threshold (i.e. ppb level);

(4) include the likelihood of hydrogen leakage impacts in decision-making (for example, hydrogen should be deployed in situations which allow for minimization of leakage, such as hubs where the hydrogen is produced and used with limited movement or in applications that represent the greatest potential benefits); and

(5) identify leakage mitigation measures and best practices (lessons learned over the past decade about how to minimize natural gas leakage are likely relevant, despite the differences in the properties of these two gases).

We also note that there are additional climate and other environmental concerns associated with deployment of hydrogen that need to be addressed, such as the diversion of renewably-produced electricity to produce green hydrogen when a potentially more effective decarbonization pathway would be to use the renewable electricity directly to offset fossil fuel use (Ueckerdt et al., 2021); NOx emissions from combusting hydrogen which is a health concern for local communities (Lewis, 2021); water availability for green hydrogen (Beswick et al., 2021; Simoes et al., 2021); and CCUS efficiency and permanence for blue hydrogen (Saadat and Gersen, 2021).

If we are to meet the climate challenge before us, it is imperative that we carefully examine each alternative decarbonization pathway using robust and appropriate metrics and data. The near- and mid-term warming impacts of hydrogen emissions are higher than widely perceived. These impacts should be explicitly and quantitatively accounted for in order to maximize the climate benefits of replacing fossil fuel systems with hydrogen. Taking a proactive and scientific approach to understand the implications of and address hydrogen leakage can help ensure that the global rush to hydrogen delivers on its promise to benefit the climate over all timescales.

\section{Code and data availability}

All code and data are available upon request. 


\section{Author contribution}

IBO and SPH conceptualized the study. IBO conducted the analysis and data visualization. IBO and SPH wrote and edited the manuscript.

\section{Competing interests}

The authors declare that they have no conflict of interest.

\section{Acknowledgements}

We would like to thank Tianyi Sun and Eriko Shrestha for project support; Fabian Paulot and Stephen Pacala for helpful discussions on the methodology; and Joan Ogden, Michael Oppenheimer, Roland Kupers, Beth Trask, Hanling Yang, Aoife O’Leary, Morgan Rote, Jane Long, Mark Brownstein, Laura Catalano, and Natasha Vidangos for thoughtful feedback on versions of the paper. This work was supported by Robertson Foundation, the Heising-Simons Foundation, and ClimateWorks Foundation.

\section{References}

Alvarez, R. A., Pacala, S. W., Winebrake, J. J., Chameides, W. L., and Hamburg, S. P.: Greater focus needed on methane leakage from natural gas infrastructure, P. Natl. Acad. Sci. USA, 109, 6435-6440, https://doi.org/10.1073/pnas.1202407109, 2012.

Alvarez, R. A., Zavala-Araiza, D., Lyon, D. R., Allen, D. T., Barkley, Z. R., Brandt, A. R., Davis, K. J., Herndon, S. C., Jacob, D. J., Karion, A., Kort, E. A., Lamb, B. K., Lauvaux, T., Maasakkers, J. D., Marchese, A. J., Omara, M., Pacala, S. W., Peischl, J., Robinson, A. L., Shepson, P. B., Sweeney, C., Townsend-Small, A., Wofsy, S. C., and Hamburg, S. P.:

535 Assessment of methane emissions from the U.S. oil and gas supply chain, Science, 361, 186-188, https://doi.org/10.1126/science.aar7204, 2018.

Bartlett, J. and Krupnick, A.: Decarbonized Hydrogen in the US Power and Industrial Sectors: Identifying and Incentivizing Opportunities to Lower Emissions, Resources for the Future, 2020.

Beswick, R. R., Oliveira, A. M., and Yan, Y.: Does the Green Hydrogen Economy Have a Water Problem?, Am. Chem. S., 6, 3167-3169, https://doi.org/10.1021/acsenergylett.1c01375, 10 September 2021.

Bond, S. W., Gül, T., Reimann, S., Buchmann, B., and Wokaun, A.: Emissions of anthropogenic hydrogen to the atmosphere during the potential transition to an increasingly H2-intensive economy, Int. J. Hydrogen, Energ., 36, 1122-1135, https://doi.org/10.1016/j.ijhydene.2010.10.016, 2011.

Budsberg, E., Crawford, J., Gustafson, R., Bura, R., and Puettmann, M.: Ethanologens vs. acetogens: Environmental impacts of two ethanol fermentation pathways, Biomass Bioenerg., 83, 23-31, https://doi.org/10.1016/j.biombioe.2015.08.019, 2015. 
Camuzeaux, J. R., Alvarez, R. A., Brooks, S. A., Browne, J. B., and Sterner, T.: Influence of methane emissions and vehicle efficiency on the climate implications of heavy-duty natural gas trucks, Am. Chem. S., 49, 6402-6410, https://doi.org/10.1021/acs.est.5b00412, 2015.

Chang, Y., Zhang, C., Shi, J., Li, J., Zhang, S., and Chen, G.: Dynamic Bayesian network based approach for risk analysis of hydrogen generation unit leakage, Int. J. Hydrogen Energ., 44, 26665-26678, https://doi.org/10.1016/J.IJHYDENE.2019.08.065, 2019.

Colella, W. G., Jacobson, M. Z., and Golden, D. M.: Switching to a U.S. hydrogen fuel cell vehicle fleet: The resultant change in emissions, energy use, and greenhouse gases, J. Power Sources, 150, 150-181, https://doi.org/10.1016/J.JPOWSOUR.2005.05.092, 2005.

555 Crutzen, P. J.: Photochemical reactions initiated by and influencing ozone in unpolluted tropospheric air, Tellus, 26, 47-57, https://doi.org/10.3402/tellusa.v26i1-2.9736, 1974.

Department of Energy: Hydrogen Delivery Scenario Analysis Model (HDSAM) V3.1, https://www.hydrogen.energy.gov/h2a_delivery.html.

Derwent, R. G., Collins, W. J., Johnson, C. E., and Stevenson, D. S.: Transient behaviour of tropospheric ozone precursors in a global 3-D CTM and their indirect greenhouse effects, Climatic Change, 49, 463-487, https://doi.org/10.1023/A:1010648913655, 2001.

Derwent, R. G., Stevenson, D. S., Utembe, S. R., Jenkin, M. E., Khan, A. H., and Shallcross, D. E.: Global modelling studies of hydrogen and its isotopomers using STOCHEM-CRI: Likely radiative forcing consequences of a future hydrogen economy, Int. J. Hydrogen Energ., 45, 9211-9221, https://doi.org/10.1016/j.ijhydene.2020.01.125, 2020.

565 Derwent, R. G.: Hydrogen for Heating: Atmospheric Impacts, Ph.D., Department for Business, Energy \& Industrial Strategy, 2018.

Derwent, R., Simmonds, P., O’doherty, S., Manning, A., Collins, W., and Stevenson, D.: Global environmental impacts of the hydrogen economy, Int. J. Nuclear Hydrogen Production and Application, 1, 57-67, https://doi.org/10.1504/IJNHPA.2006.009869, 2006.

570 Ehhalt, D., Prather, M., Dentener, F., Derwent, R., Dlugokencky, E., Holland, E., Isaksen, I., Katima, J., Kirchhoff, V., Matson, O., Midgley, P., and Wang, M.: Atmospheric Chemistry and Greenhouse Gases, in: Climate Change 2001: The Scientific Basis, Contribution of Working Group I to the Third Assessment Report of the Intergovernmental Panel on Climate Change, edited by: Houghton, J. T., Ding, Y., Griggs, D. J., Noguer, M., van der Linden, P. J., Dai, X., Maskell, K., and Johnson, C. A., Cambridge University Press, Cambridge, United Kingdom and New York, NY, USA, 239-287, 2001.

575 Field, R. A. and Derwent, R. G.: Global warming consequences of replacing natural gas with hydrogen in the domestic energy sectors of future low-carbon economies in the United Kingdom and the United States of America, Int. J. Hydrogen Energ., 46, 30190-30203, https://doi.org/10.1016/j.ijhydene.2021.06.120, 2021.

Fischer, E. M., Sippel, S., and Knutti, R.: Increasing probability of record-shattering climate extremes, Nat. Clim. Change, 11, 689-695, https://doi.org/10.1038/s41558-021-01092-9, 2021.

580 Forster, P., Storelvmo, T., Armour, K., Collins, W., Dufresne, J. L., Frame, D., Lunt, D. J., Mauritsen, T., Palmer, M. D., Watanabe, M., Wild, M., and Zhang, H.: The Earth's energy budget, climate feedbacks, and climate sensitivity, in: Climate Change 2021: The Physical Science Basis, Contribution of Working Group I to the Sixth Assessment Report of the Intergovernmental Panel on Climate Change, Cambridge University Press, page, 2021. 
Global Hydrogen Review 2021, International Energy Agency, 2021.

Hajji, Y., Jouini, B., Bouteraa, M., Elcafsi, A., Belghith, A., and Bournot, P.: Numerical study of hydrogen release accidents in a residential garage, Int. J. Hydrogen Energ., 40, 9747-9759, https://doi.org/10.1016/J.IJHYDENE.2015.06.050, 2015.

Howarth, A. and Jacobson, M. Z.: How green is blue hydrogen?, Energy Sci. Eng., 9, 1676-1687, https://doi.org/https://doi.org/10.1002/ese3.956, 2021.

Hydrogen decarbonization pathways A life-cycle assessment, Hydrogen Council, 2021.

Hydrogen decarbonization pathways Potential supply scenarios, Hydrogen Council, 2021.

Hydrogen Economy Outlook Key messages, BloombergNEF, 2020.

Hydrogen Insights Report 2021, Hydrogen Council, 2021.

Hydrogen scaling up A sustainable pathway for the global energy transition, Hydrogen Council, 2017.

Ivanovich, C. C., Ocko, I. I., Piris-Cabezas, P., and Petsonk, A.: Climate benefits of proposed carbon dioxide mitigation

595 strategies for international shipping and aviation, Atmos. Chem. Phys., 19, 14949-14965, https://doi.org/10.5194/acp-1914949-2019, 2019.

Jacobson, M. Z.: Effects of wind-powered hydrogen fuel cell vehicles on stratospheric ozone and global climate, Geophys. Res. Lett., 35, https://doi.org/10.1029/2008GL035102, 2008.

Kobayashi, H., Naruo, Y., Maru, Y., Takesaki, Y., and Miyanabe, K.: Experiment of cryo-compressed (90-MPa) hydrogen leakage diffusion, Int. J. Hydrogen Energ., 43, 17928-17937, https://doi.org/10.1016/J.IJHYDENE.2018.07.145, 2018.

Levy, H.: Photochemistry of the lower troposphere, Planet. Space Sci., 20, 919-935, https://doi.org/10.1016/00320633(72)90177-8, 1972.

Lewis, A. C.: Optimising air quality co-benefits in a hydrogen economy: a case for hydrogen-specific standards for NOx emissions, Environ. Sci: Atmos., 1, 201-207, https://doi.org/10.1039/d1ea00037c, 2021.

605 Mejia, A. H., Brouwer, J., and mac Kinnon, M.: Hydrogen leaks at the same rate as natural gas in typical low-pressure gas infrastructure, Int. J. Hydrogen Energ., 45, 8810-8826, https://doi.org/10.1016/j.ijhydene.2019.12.159, 2020.

Melaina, M. W., Antonia, O., and Penev, M.: Blending Hydrogen into Natural Gas Pipeline Networks: A Review of Key Issues, Ph.D., National Renewable Energy Laboratory, 2013.

Myhre, G., Shindell, D., Bréon, F.-M., Collins, W., Fuglestvedt, J., Huang, J., Koch, D., Lamarque, J.-F., Lee, D., Mendoza,

610 B., Nakajima, T., Robock, A., Stephens, G., Takemura, T., and Zhang, H.: Anthropogenic and Natural Radiative Forcing Supplementary Material, in: Climate Change 2013: The Physical Basis, Contribution of Working Group I of the Fifth Assessment Report of the Intergovernmental Panel on Climate Change, edited by: Stocker, T.F., Qin, D., Plattner, G.-K., Tignor, M. Allen, S.K., Boschung, J., Nauels, A., Xia, Y., Bex, V., Midgley, P.M., 2013.

Najjar, Y. S.: Hydrogen Leakage Sensing and Control: (Review), Biomed. J. Sci. Tech. Res., 21, 615 https://doi.org/10.26717/bjstr.2019.21.003670, 2019.

Ocko, I. B. and Hamburg, S. P.: Climate Impacts of Hydropower: Enormous Differences among Facilities and over Time, Environ. Sci. Technol., 53, 14070-14082, https://doi.org/10.1021/acs.est.9b05083, 2019. 
Ocko, I. B., Hamburg, S. P., Jacob, D. J., Keith, D. W., Keohane, N. O., Oppenheimer, M., Roy-Mayhew, J. D., Schrag, D. P., and Pacala, S. W.: Unmask temporal trade-offs in climate policy debates, Science, 356,

Ocko, I. B., Sun, T., Shindell, D., Oppenheimer, M., Hristov, A. N., Pacala, S. W., Mauzerall, D. L., Xu, Y., and Hamburg, S. P.: Acting rapidly to deploy readily available methane mitigation measures by sector can immediately slow global warming, Environ. Res. Lett., 16, https://doi.org/10.1088/1748-9326/abf9c8, 2021.

Parvini, M. and Gharagouzlou, E.: Gas leakage consequence modeling for buried gas pipelines, J. Loss. Prevent. Proc., 37, 110-118, https://doi.org/10.1016/J.JLP.2015.07.002, 2015.

Paulot, F., Paynter, D., Naik, V., Malyshev, S., Menzel, R., and Horowitz, L. W.: Global modeling of hydrogen using GFDL-AM4.1: Sensitivity of soil removal and radiative forcing, Int. J. Hydrogen Energ., 46, 13446-13460, https://doi.org/10.1016/j.ijhydene.2021.01.088, 2021.

Prather, M. J.: An Environmental Experiment with H2?, Science, 302, https://doi.org/10.1126/science.1091060, 24 October 2003.

Qian, J.Y., Li, X.J., Gao, Z.X., and Jin, Z.J.: A numerical study of hydrogen leakage and diffusion in a hydrogen refueling station, Int. J. Hydrogen Energ., 45, 14428-14439, https://doi.org/10.1016/J.IJHYDENE.2020.03.140, 2020.

Rahn, T., Eiler, J. M., Boering, K. A., Wennberg, P. O., McCarthy, M. C., Tyler, S., Schauffler, S., Donnelly, S., and Atlas, E.: Extreme deuterium enrichment in stratospheric hydrogen and the global atmospheric budget of H2, Nature, 424, 915918, https://doi.org/https://doi.org/10.1038/nature01917, 2003.

Saadat, S. and Gersen, S.: Reclaiming Hydrogen for a Renewable Future, Earthjustice, 1-41 pp., 2021.

Schultz, M. G., Diehl, T., Brasseur, G. P., and Zittel, W.: Air Pollution and Climate-Forcing Impacts of a Global Hydrogen Economy, 302, 622-624, https://doi.org/10.1126/science.1089527, 2003.

Shen, L., Zavala-Araiza, D., Gautam, R., Omara, M., Scarpelli, T., Sheng, J., Sulprizio, M. P., Zhuang, J., Zhang, Y., Qu, Z.,

640 Lu, X., Hamburg, S. P., and Jacob, D. J.: Unravelling a large methane emission discrepancy in Mexico using satellite observations, Remote Sens. Enviornment, 260, https://doi.org/10.1016/j.rse.2021.112461, 2021.

Sherif, S. A., Zeytinoglu, N., and Veziroglug, T. N.: Liquid Hydrogen : Potential, Problems, and a Proposed Research Program, Int. J. Hydrogen Energy, 22, 683-688, 1997.

Simoes, S. G., Catarino, J., Picado, A., Lopes, T. F., di Berardino, S., Amorim, F., Gírio, F., Rangel, C. M., and Ponce de

645 Leão, T.: Water availability and water usage solutions for electrolysis in hydrogen production, J. Clean. Produc., 315 , https://doi.org/10.1016/j.jclepro.2021.128124, 2021.

Swain, M. R. and Swain, M. N.: A comparison of H2, CH4 and C3H8 fuel leakage in residential settings, Int. J. Hydrogen Energ., 17, 807-815, https://doi.org/10.1016/0360-3199(92)90025-R, 1992.

The Future of Hydrogen, International Energy Agency, 2019.

650 Tromp, T. K., Shia, R.-L., Allen, M., Eiler, J. M., and Yung, Y. L.: Potential Environmental Impact of a Hydrogen Economy on the Stratosphere, Science, 300, 1740-1742, https://doi.org/10.1126/science.1085169, 2003.

Ueckerdt, F., Bauer, C., Dirnaichner, A., Everall, J., Sacchi, R., and Luderer, G.: Potential and risks of hydrogen-based efuels in climate change mitigation, Nat. Clim. Change, 11, https://doi.org/10.1038/s41558-021-01032-7, 2021.

UK Hydrogen Strategy, Secretary of State for Business, E. \& I. S.: UK Hydrogen Strategy, Parliament, 1-122, 2021. 
655 van Renssen, S.: The hydrogen solution?, Nat. Clim. Change, 10, https://doi.org/10.1038/s41558-020-0891-0, 2020.

van Ruijven, B., Lamarque, J. F., van Vuuren, D. P., Kram, T., and Eerens, H.: Emission scenarios for a global hydrogen economy and the consequences for global air pollution, Glo. Env. Change, 21, 983-994, https://doi.org/10.1016/j.gloenvcha.2011.03.013, 2011.

Vogel, B., Feck, T., and Groobß, J. U.: Impact of stratospheric water vapor enhancements caused by CH4 and H2O increase 660 on polar ozone loss, J. Geophys. Res-Atmos., 116, https://doi.org/10.1029/2010JD014234, 2011.

Vogel, B., Feck, T., Grooß, J. U., and Riese, M.: Impact of a possible future global hydrogen economy on Arctic stratospheric ozone loss, Energy Environ. Sci., 5, https://doi.org/10.1039/c2ee03181g, 2012.

Wang, D., Jia, W., Olsen, S. C., Wuebbles, D. J., Dubey, M. K., and Rockett, A. A.: Impact of a future H2-based road transportation sector on the composition and chemistry of the atmosphere -- Part 2: Stratospheric ozone, Atmos. Chem.

665 Phys., 13, 6139-6150, https://doi.org/https://doi.org/10.5194/acp-13-6139-2013, 2013.

Warwick, N. J., Bekki, S., Nisbet, E. G., and Pyle, J. A.: Impact of a hydrogen economy on the stratosphere and troposphere studied in a 2-D model, Geophys. Res. Letters, 31, https://doi.org/10.1029/2003gl019224, 2004.

Working Paper | National Hydrogen Strategies, World Energy Council, 2021.

Wuebbles, D. J., Dubey, M. K., Edmonds, J., Layzell, D., Olsen, S., Rahn, T., Rocket, A., Wang, D., and Jia, W.: Evaluation of the Potential Environmental Impacts from Large-Scale Use and Production of Hydrogen in Energy and Transportation Applications, University of Illinois at Urbana-Champaign, United States, https://doi.org/https://doi.org/10.2172/1044180, 2010.

Xu, Y., Zaelke, D., Velders, G. J. and Ramanathan, V.: The role of HFCs in mitigating 21st century climate change, Atmos. Chem. Phys., 13, 6083-6089, 2013. 